\title{
BEROSUS ELSAE, NUEVA ESPECIE DE COLEÓPTERO ACUÁTICO (HIDROPHILIDAE: HYDROPHILINAE: BEROSINI) DE UN MICROHÁBITAT ANPOGENO EN LA PENÍNSULA DE ARAYA, VENEZUELA
}

\section{Berosus elsae, new species of aquatic Coleoptera (Hidrophilidae: Hydrophilinae: Berosini) from an anpogeno microhabit of the Araya Peninsula, Venezuela}

\begin{abstract}
Mauricio García ${ }^{1, ~ *}$ y Erickxander Jesús Jiménez-Ramos ${ }^{2,3}$
${ }^{1}$ Centro de Investigaciones Biológicas (CIB), Facultad de Humanidades y Educación, Universidad del Zulia, Apartado 526, Maracaibo A-4001, Estado Zulia, Venezuela; (1) orcid.org/0000-0003-3238-9527. 'Laboratorio de Ecología, Departamento de Biología, Escuela de Ciencias, Universidad de Oriente (UDO). Cerro Colorado, Cumaná, Estado Sucre 6101.Venezuela. ${ }^{3}$ Coordinación de Proyectos de Investigación, Universidad Politécnica Territorial de Oeste de Sucre Clodosbaldo Russian, Sede Araya, estado Sucre, 6101. Venezuela; (1) orcid.org/0000-0002-3706-0483. "Para correspondencia: liocanthydrus@yahoo.com.
\end{abstract}

\section{RESUMEN}

Se describe Berosus elsae, una nueva especie de la familia Hydrophilidae, en un sistema hidroecológico antropogénico (artificial) altamente contaminado de la Península de Araya. Se ilustra el habitus dorsal, órganos genitales y otros escleritos de interés diagnóstico con una breve descripción del microhábitat anpogeno o lugar de recolección de la nueva especie. Berosus elsae sp. nov., representa el primer registro del género Berosus Leach, para la región nororiental de Venezuela, siendo además la primera especie del género reportada para la franja caribeña de Sudamérica. Por su hábitat y distribución geográfica, Berosus elsae sp. nov. estaría más emparentada con las especies Centroamericanas y del Caribe, que con las especies de Berosus descritas para Sudamérica. Se incluyen imágenes satelitales de la localidad y fotografías del microhábitat anpogeno.

Palabras clave: Araya, coleóptero acuático, Hydrophilidae, lagunas de oxidación, nueva especie.

\section{ABSTRACT}

A new species in the family Hydrophilidae, Berosus elsae is described, in a highly polluted hydro-ecological system on the Araya Peninsula. The dorsal habitus, genital organs and other sclerites of diagnostic interest are illustrated and the anpogeno microhabitat where the described species was collected is described. Berosus elsae sp. nov., represents the first record of the genus Berosus Leach, for the northeastern region of Venezuela, being also the first species of the genus reported for the Caribbean strip of South America. Due to its habitat and geographic distribution, Berosus elsae sp. nov. would be more related to Central American and Caribbean species than to the Berosus species described for South America. Satellite images of the locality and photographs of the anpogeno microhabitat are included.

Keyworlds: Araya, aquatic beetle, Hydrophilidae, oxidation ponds, new species.

\section{INTRODUCCIÓN}

El género Berosus Leach, preseta una amplia distribución global con más de 273 especies (Hansen, 1999; Short y Fikáček, 2011). Para Venezuela, se registra un total de 36 especies del género (Oliva y Short, 2012), distribuidas principalmente entre la región de los llanos y el sur del país. La presente investigación, permitió describir ua nueva especie del género Berosus, 
procedente de un ambiente altamente contaminado identificado como lagunas de oxidación (estabilización) "El Cardonal". Esta se diferencia por la coloración negra brillante de la cabeza, en contraste con las especies reportadas por Oliva y Short (2012), que presentan la cabeza de color negro metalizado, un carácter que también le separa de las especies descritas para el Caribe (Deler-Hernández et al. 2013). Lo mismo ocurre con la forma del ápice del quinto ventrito abdominal, el cual presenta un doble-escote de base redondeada frente a los escotes con base agudas o bipuntadas de las especies caribeñas (Deler-Hernández et al. 2013).

\section{OBJETIVO}

- El propósito de esta investigación es la descripción y registro de una nueva especie de coleóptero acuático de la familia Hydrophilidae colectado en un microhábitat anpogeno de un sistema antropogénico, en la costa peninsular de Araya en Venezuela.

\section{MATERIALES Y MÉTODOS}

El área de estudio constituye un sistema hidroecológico artificial de aguas residuales, denominada como lagunas de estabilización-oxidación (10³5'16.74” N y 64¹5'12.54” O), situadas en la localidad de Araya, region occidental de la península de Araya, nororiente de Venezuela a una elevación de $9 \mathrm{~m}$. Las características habitalógicas del medio artificial (microhábitat anpogeno), como parte de un sistema hidroecológico antropogénico se describen en García et al. (2016).

Material examinado. La muestra examinada corresponde a un ejemplar hembra, que fue depositado en la colección referencial del Museo de Artrópodos de la Universidad del Zulia (MALUZ). La colecta se realizó de forma manual, durante la captura de otras especies de hemípteros acuáticos, utilizando una malla para capturas acuáticas y un succionador como dispositivo de extracción para ejemplares pequeños.

Para la determinación e identificación se utilizó un estereomicroscopio marca Leica M10 con lente plana, $80 \mathrm{X}$ de resolución y objetivos $25 \mathrm{X}$. La extracción de los genitales se realizó sumergiendo al ejemplar en un baño térmico entre 3 y 4 minutos, produciendo ablandamiento de los tejidos, posteriormente se extrajeron los escleritos genitales, fueron lavados en $\mathrm{KOH} 10 \%$ y conservados en microfrascos con solución alcohólica de glicerina.

Las ilustraciones se obtuvieron con cámara lúcida y mejorada con el programa de diseño vectorial Inkscape versión 0.92. Las imágenes aéreas se obtuvieron con el programa Google Earth.

\section{RESULTADOS Y DISCUSIÓN}

Taxonomía

Berosus elsae García y Jiménez-Ramos, especie nueva

(Figs. 1-3)

Diagnósis. Especie grande de cuerpo alargado con la cabeza de color negro, brillante, finamente puntuada; la superficie dorsal es finamente puntuada. Pronoto liso y brillante, muy finamente puntuado. Élitros con finos surcos longitudinales que presentan hileras de puntos grueso contínuos, finalizando en un ápice liso y simple, angulado, sin algún tipo de escotadura o extensiones lobulares como espinas apicales. Mentón con superficie lisa, escasamente puntuada con puntos anchos y ampliamente separados; margen anterior sinuoso con un dentículo basal 
a cada lado y ápice angulado; margen posterior ligeramente recto en los lados y redondeado en el ápice. Prosterno con una serie de pelos largos en la región central, de márgenes ensanchado en los extremos, y con proceso prosternal corto, muy angosto y una fina e irregular carena longitudimedial. Cresta mesoventral muy delgada, con el mergen superior escotado, dando lugar a dos lóbulos anchos, con una serie de puntos setiferos a todo lo largo. Margen posterior del ventrito abdominal $\mathrm{V}$, con un ancho escote apical, que da lugar a dos lóbulos aguzados (uno a cada lado) como dentículos gruesos; margen interior redondeado formando dos cavidades anchas.

Diagnosis. Large, long-bodied species with a shiny black head, finely punctuated; the dorsal surface is finely punctuated. Smooth and shiny pronotum, very finely punctuated. Elytra with fine longitudinal grooves that present rows of thick continuous points, ending in a smooth and simple apex, angled, without any type of notch or lobular extensions such as apical spines. Chin with smooth surface, sparsely punctuated with wide and widely separated points; sinuous anterior margin with a basal denticle on each side and angled apex; posterior margin slightly straight on the sides and rounded at the apex. Prosternal with a series of long hairs in the central region, with margins widened at the ends, and with a short, very narrow prosternal process and a fine and irregular longitudinal medial fairing. Very thin mesoventral ridge, with a low cut upper margin, giving rise to two wide lobes, with a series of setiferous points throughout. Posterior margin of the abdominal ventrite $\mathrm{V}$, with a wide apical neckline, giving rise to two pointed lobes (one on each side) as thick denticles; rounded inner margin forming two wide cavities.

Localidad tipo. Península de Araya, nororiente de Venezuela.

Material tipo. Holotipo 9 , Venezuela, Sucre, Península de Araya, Araya, lagunas de estabilización-oxidación (10³5'16.74" N y 64¹5'12.54” O), 9 m, 17.xii.2018, M. García y E. Jiménez, depositado en el Museo de Artrópodos de La Universidad del Zulia (MALUZ).

Descripción holotipo. Forma oval con el margen anterior angosto, ensanchado posteriormente (Fig. 1). Largo $6.1 \mathrm{~mm}$ y ancho $2.5 \mathrm{~mm}$. Exceptuando la coloración negra brilante de la cabeza y el labro, dorsalmente es testácea con algunas manchas y puntuaciones obscuras en la superficie elitral a nivel del margen comisural. Antenas y palpos testáceo. Ventralmente con el mentón, submentón negro brillante y la gula es de una tonalidad negra opaca, prosterno pardo, mesoventrito negro, metaventrito negro con parches claros y abdomen con $3 / 4$ negro y una franja marginal amarilla en el ápice. Coxas, trocánteres, fémures, tibias y tarsos pardo obscuro. La superficie de la cabeza es densamente punteada, puntos separados por su diámetro. Ojos abultados separados por tres veces su diámetro. Sutura fronto clipeal gruesa y ligeramente abultada entre el vertex y los ojos. Labro pequeño, con la superficie densamente punteada. Margen anterior y posterior con hileras de pelos largos, delgados y dorados. Margen anterior ligeramente extendido anteromedialmente. Palpo maxilar (Fig. 2) con el palpómero I muy corto y globular; palpómero II largo, angosto en la base, ligeramente curvo y ensanchado hacia el ápice redondeado; palpómero III corto, triangular, de la mitad de la longitud del II; palpómero IV largo, curvo, ligeramente más largo que el II. Palpos labiales (Fig. 2) robustos con el palpómero I muy corto; palpómero II largo, angosto en la base y abultado hacia el ápice, varios pelos largos y dorados en el ápice y en la base; palpómero III corto, subcilíndrico, de igual longitud que el II, con dos pelos en la mitad. Antena (Fig. 2) con siete antenómeros: antenómero I, largo, curvo y abultado en la mitad apical; antenómero II largo, cilíndrico, la mitad de la longitud del I; antenómero III largo, delgado, la mitad del III angosto en la base y ensanchado en el ápice; antenómero IV corto, ancho y cupular; antenómeros V, VI y VII, anchos y pubescentes, formando el mazo. Mentón subrectangular; margen anterior angulado anteromedialmente, con dos dentículos laterales, uno a cada lado; margenes laterales extendidos 
oblicuamente y el margen posterior ligeramente sinuoso (Fig. 2); superficie del mentón lisa y brillante, con puntos espaciados. Submentón horizontal con la mitad apical lisa y brillante y la mitad basal abultada y rugosa. Gula con la superficie rugosa. Pronoto con puntuaciones finas sobre la superficie discal, separadas por su diámetro. Escutelo largo y triangular. Élitros con la superfice surcada con 12 hileras de pequeñas depresiones hasta el ápice; espacio entre surcos con finos puntos negros. Ápice elitral angulado, no modificado ni lobulado. Prosterno fino a los lados, con los extremos ancho y longitumedialmente carenado y extendido, formando una especie de cuernos (Fig. 2). Margen anterior carenado. Mesoventrito escasamente pubescente, con los márgenes laterales gruesamente carenado en el borde de la cavidad mesocoxal y el pequeño disco mesoventral con dos gruesas carenas formando una $\mathrm{V}$, espacio entre carena liso y plano (Fig. 2). Protuberancia mesoventral formando una carena laminal con varios setíferos sobre el ápice, con aspecto de quilla (Fig. 2). Metaventrito con la superficie finamente rugosa y pubescente; disco metaventral abultado, con un óvalo glabro y brillante. Abdomen con los cinco ventritos pubescentes; ventrito $\mathrm{V}$ con el margen apical con doble escotadura, separadas por un tabique grueso de margen redondeado. Procoxa y trocánter pubescentes, profémur pubescente en su mitad basal. Tibia delgada y espinosa en los márgenes de igual longitud del fémur y tarsos cortos y cilíndrico con el tarsómero cinco abultado en su mitad apical, con dos uñas largas y curvas (Fig. 3). Mesocoxa y trocánter pubescentes, mesofémur pubescente en $2 / 3$ de la superficie basal. Tibia larga y delgada en la base, con márgenes espinosos, de igual longitud que el fémur y tarsos largos y delgados con el tarsómero V abultado en su mitad apical, con dos uñas largas, delgadas y curvas, del largo de la tibia. Metacoxa y trocánter pubescentes, metafémur pubescente en $2 / 3$ de su longitud. Tibia delgada con márgenes espinosos del largo del fémur y tarsos largos y cilíndricos, de la longitud de la tibia, con el tarsómero $\mathrm{V}$ abultado en mitad apical con dos uñas largas, delgadas y curvas. Órgano génital con la gonocoxa ancha y redondeada. Gonocoxito con dos gonocoxómeros, uno basal, largo, ancho en la base y delgado en el ápice y otro muy corto y delgado, 1/4 la longitud del I con un estilo en el ápice (Fig. 3).

\section{Macho. Desconocido.}

Etimología. Se dedica el epíteto específico a Elsa Colón, amiga y colega.

Distribución. La distribucion confirmada para la especie, corresponde al extremo noroccidental de la Península de Araya, nororiente de Venezuela, (Figs. 4, 5, 6 ), región caracterizada por su extrema aridez, fuertes vientos y temperaturas que oscilan entre 27 y $35^{\circ} \mathrm{C}$, además de poca pluviosidad.

Comentario taxonómico. Algunas especies de Berosus presentan la cabeza coloreada de negro metálico, o parcialmente negro opaco (el clípeo es pardo o castaño). Cuando la cabeza es negra o melánica, generalmente la superficie se muestra con aspecto metálico con la superficie ligeramente rugosa por las puntuaciones anchas que presenta (Oliva y Short, 2012). El caso de Berosus elsae sp. nov., es particularmente opuesto, ya que la coloración de la cabeza es completamente negra y las puntuaciones sobre la superficie son muy finas y muestran un aspecto pulido, pero a diferencia de las especies descritas y revisadas por Oliva y Short (2012) en Venezuela y el Caribe (Deler-Hernández et al., 2013), la superficie es muy brillante y no presenta aspecto rugoso, aun cuando es densamente punteada, es decir, la superficie es reflectante y no existe ningún aspecto metálico en toda la superficie cefálica. Sin embargo la coloración podría variar dependiendo de la edad del ejemplar. Según Oliva (1989) la coloración negra de la cabeza es más clara y menos compacta cuando los ejemplares son muy jóvenes. Debido que solo contamos con un solo ejemplar adulto, no es posible determinar por el momento este razonamiento. Este carácter separa a $B$. elsae sp. nov., del resto de las especies de Berosus suramericana y centroamericana. 


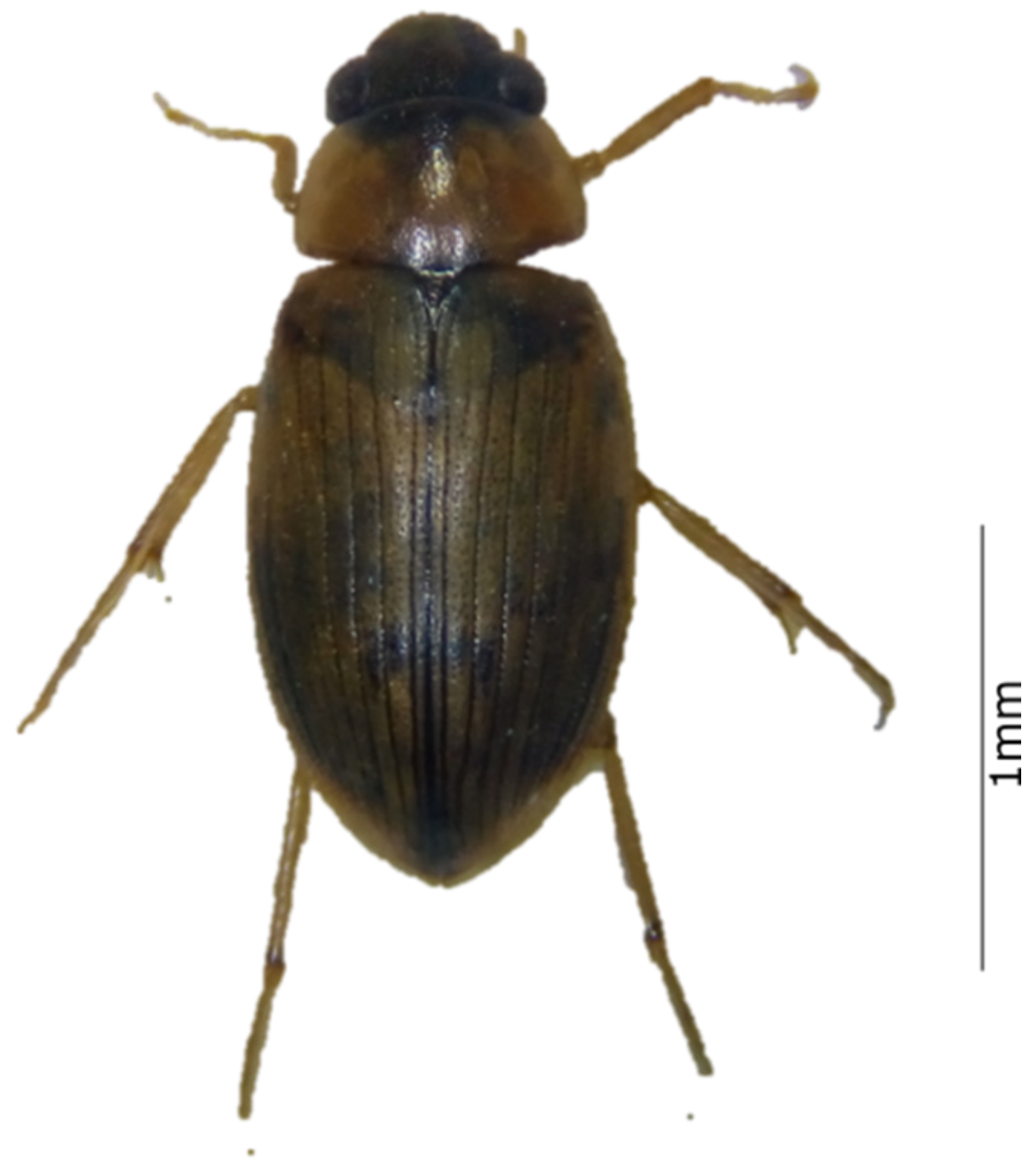

Figura 1. Habitus de Berosus elsae sp. nov. 

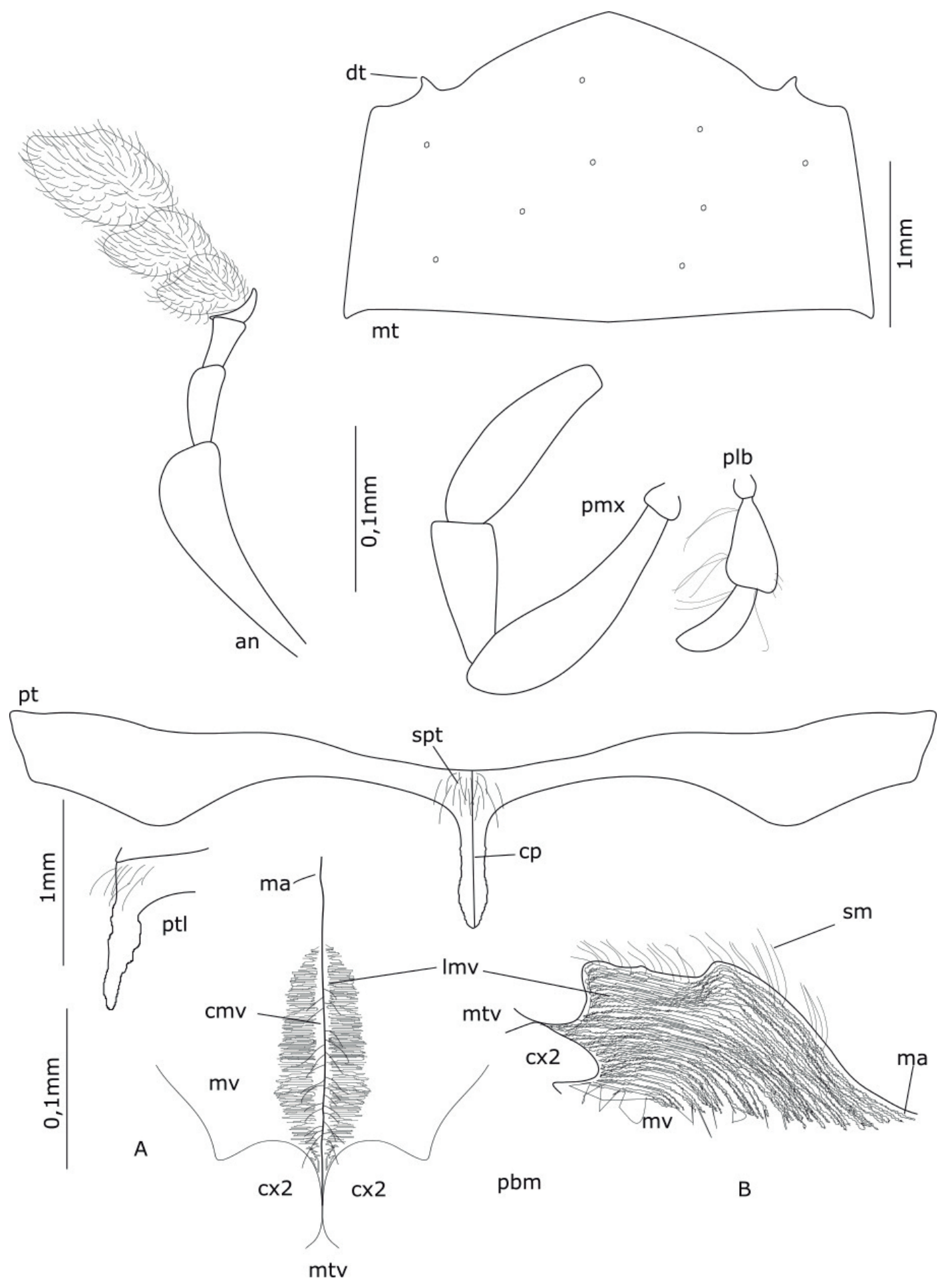

Figura 2. Escleritos de Berosus elsae sp. nov. Detalle: an = antena con siete antenómeros; pmx = palpo maxilar; plb= palpo labial; $\mathrm{mt}=$ mentón; $\mathrm{dt}=$ dentículo marginal lateral; $\mathrm{pt}=$ prosterno $; \mathrm{cp}=$ carena prosternal; $\mathrm{spt}=$ setiferos prosternal; $\mathrm{ptl}=\mathrm{prosterno}$ vista lateral; $\mathrm{mv}=$ mesoventrito; $\mathrm{pbm}=$ protuberancia mesoventral. $\mathrm{A}$, vista fronto-ventral. $\mathrm{B}$, vista lateral: ma $=$ margen anterior; $\mathrm{cmv}=$ carena mesoventral; $1 \mathrm{mv}=$ lamina mesoventral; $\mathrm{sm}=$ setiferos mesoventral; $\mathrm{mtv}=$ metaventrito; $\mathrm{cx} 2=$ cavidad mesocoxal. 


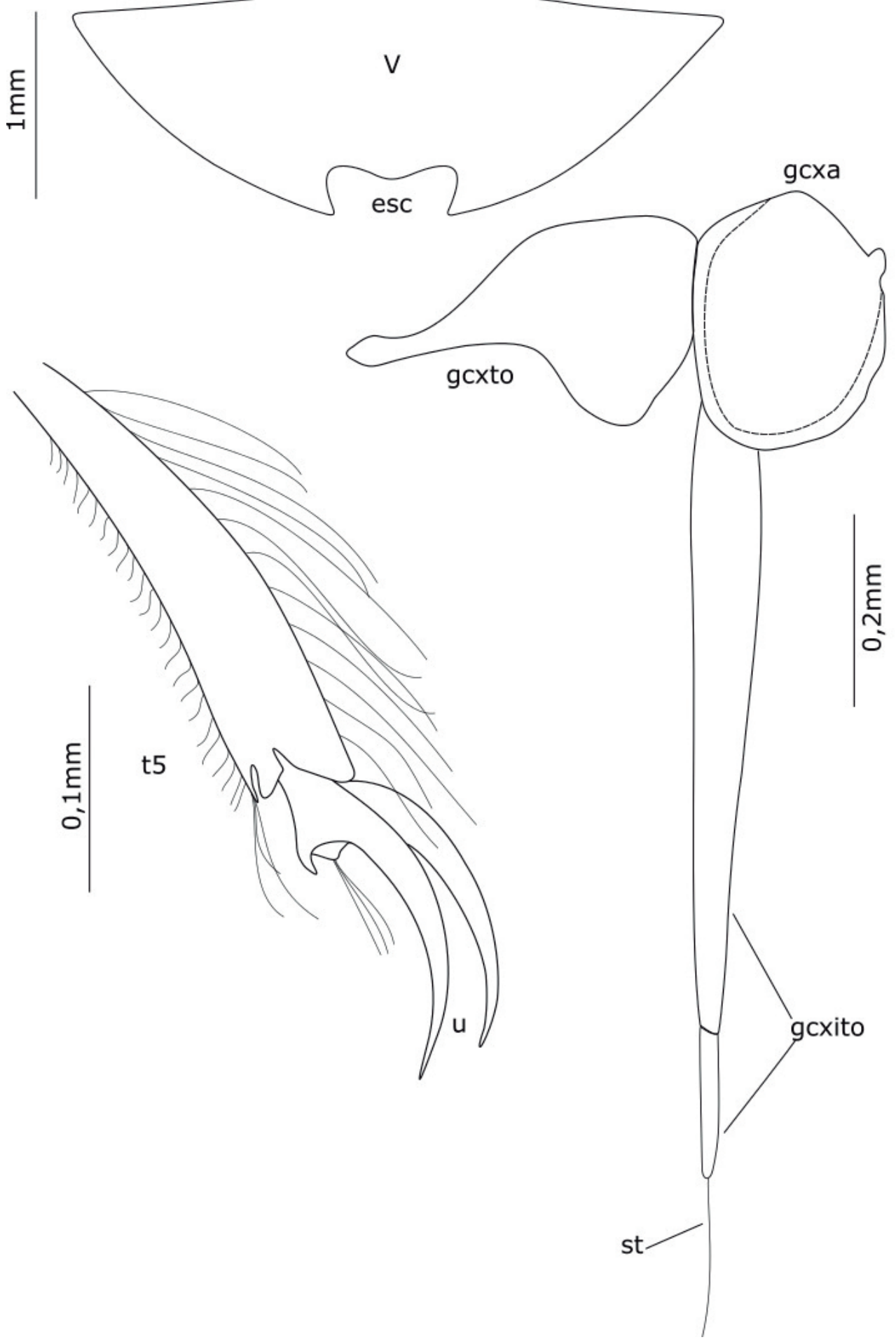

Figura 3. Abdomen, tarso y esclerito genital de la hembra de Berosus elsae sp. nov. V= quinto ventrito abdominal; esc = margen apical escotado; 5 = quinto tarsómero; $\mathrm{U}=$ uñas; gcxto = gonocoxoesternito; gcxa = gonocoxa; gcxito = gonocoxitos; $\mathrm{st}=$ estilo. 
El pronoto de Berosus elsae sp. nov. es simple, la superficie es lisa y brillante con pocas puntuaciones finas y espaciadas. El margen posterior es muy particular, al ser atenuado con el margen posteromedial recto. Este carácter es poco frecuente entre las especies de Venezuela. El esculpido elitral es más simple que el resto de las especies revisadas en Venezuela, al presentar una superficie finamente punteada y surcos longitudinales finos, con hileras de puntos sumamente ordenados. El ápice elitral es completo sin ningún tipo de modificación marginal. El ejemplar descrito corresponde con una hembra, por lo que es difícil incluir a la nueva especie en un grupo particular del género revisado por Oliva y Short (2012). Esto se debe a que los grupos de Berosus están caracterizados por la morfología del órgano genital del macho. Sin embargo queda claro que no pertenece a ninguno de los ya establecidos por ambos autores en la revisión del género en Venezuela.

Existe muy pocas variaciones en cuanto a la morfología de ambos sexo en las especies de Berosus, exceptuando su dimensión o tamaño de los ejemplares. Generalmente la hembra supera al macho en cuanto a la longitud se refiere. Solo en algunos casos la coloración de la hembra puede variar en cuanto a la coloración del macho y generalmente consiste en coloraciones incompletas o parciales en unos machos o hembras y completa en otros machos o hembras. Por lo que las diferencias de Berosus elsae sp. nov. con respecto al macho, no son de mucha relevancia (Oliva, 1989).

Biogeografía. En Oliva (2014) se presenta una distribución de las especies suramericana con base al tipo de sistemas de cuencas presente en la geografía. Siguiendo el caso, las especies de la región oriental en el estado Sucre, descritas para Venezuela por Oliva y Short (2012), se encuentran distribuidas en el sistema de cuencas del Río Orinoco.

La doble península del estado Sucre en su extremo occidental o Península de Araya, región árida y seca se corresponde con la cuenca del Golfo de Cariaco y el extremo oriental o Península de Paria, exuberantemente verde y húmeda se corresponde con la cuenca del Golfo de Paria (Figs. 4, 5 y 6). La distribución de Berosus elsae sp. nov. se enmarca en la cuenca del Golfo de Cariaco, representando un nuevo grupo de distribución para las especies de Berosus en Venezuela. Berosus elsae sp. nov. estaría conectada más con las especies costeras del Caribe y Centroamérica en vez de la especies suramericana (Oliva, com. pers.). Las especies de Berosus que se encuentran al sur de Venezuela, están muy emparentadas con las especies de Brasil, las cuales están distribuidas hasta la región de los llanos (Oliva y Short, 2012; Oliva, 2014).

Habitalogía. La especie fue recolectada en el hercircum de un hábitat anpogeno, de una laguna de aguas residuales en un sistema hidroecológico antropogénico o artificial (García et al., 2016). Las lagunas de estabilización u oxidación "El Cardonal” (Fig. 7), están ubicadas en las cercanías del sector Cerro El Macho.

Este sistema de lagunas, está conformado por cuatro estructuras rectangulares de $25 \mathrm{~m}$ de largo por $10 \mathrm{~m}$ de ancho, entre 2 y $3 \mathrm{~m}$ de profundidad, dispuestas en grupos paralelos de dos, cercanas entre sí; el mismo ha sido utilizado para el reciclaje o aprovechamiento del agua servida o residual (cloacal), un medio rico en detritus orgánico, lo que favorece la colonización por organismos acuáticos, entre ellos los insectos.

El agua residual proveniente de los sectores cercanos, es descargada en una laguna inicial, la cual, vierte a otra continua a ella, una vez que ha superado el límite de desagüe o la acumulación de material biológico en descomposición; la acumulación de material orgánico atrae a organismos que se alimentan de este, convirtiéndose en lugares propicios para la reproducción y hábitats de un gran número de especies acuáticas que necesitan el medio húmedo en las primeras etapas 


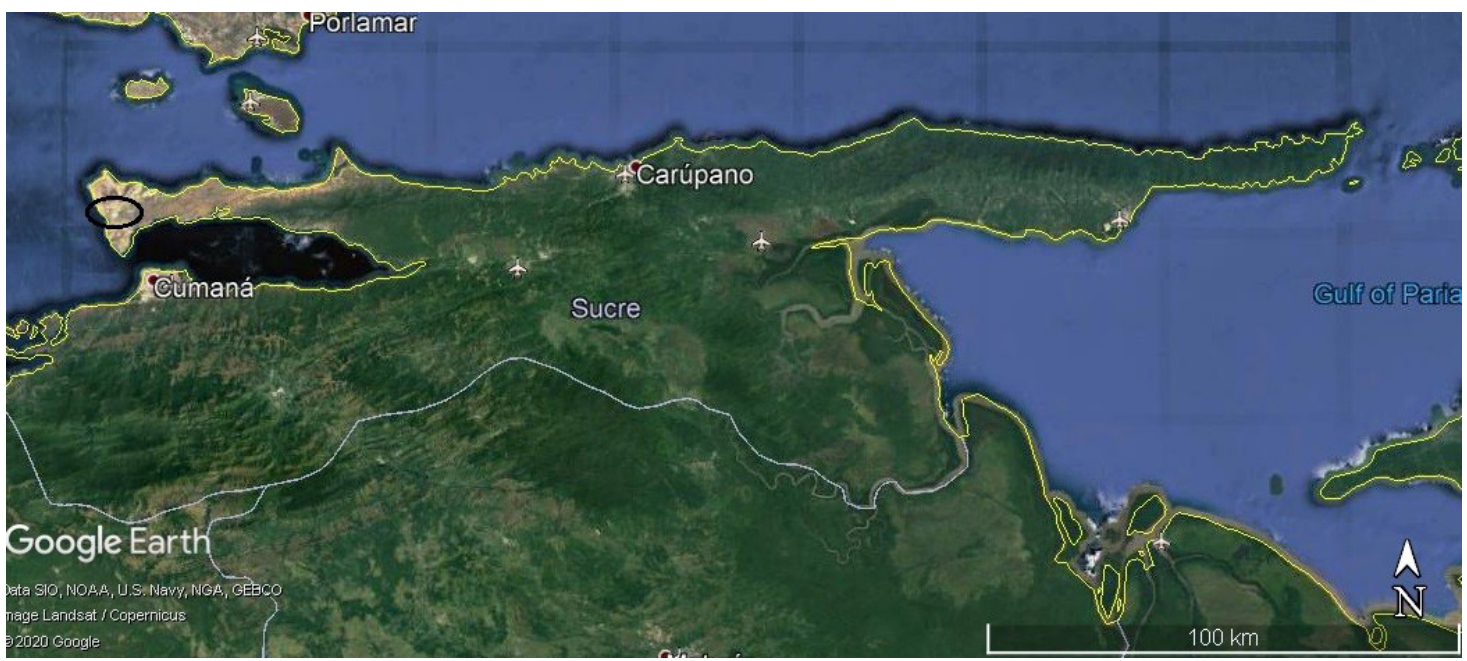

Figura 4. Imagen satelital del estado Sucre, Venezuela. El óvalo negro señala la localidad del sistema lagunar antropogénico.

de su ciclo de vida, y en hábitats de poblaciones microbianas (bacterias, algas y protozoos) que ayudan a eliminar de forma natural a diferentes patógenos contenidos en los excrementos humanos, sólidos en suspensión y materia orgánica. Las lagunas, al igual que el resto de la península, sufre una alternancia entre sequía y lluvia (Cumana, 1999).

Los alrededores de este complejo lagunar presentan una vegetación característicamente xerófila donde las familias Cactaceae y Caesalpinaceae son las mejores representadas, con algunos ejemplares de las familias Fabaceae y Poaceae; las especies suculentas, caducifolias, herbáceas y arbustivas constituyen la vegetación dominante. En el interior de las lagunas, la vegetación dominante está representada por Juncaceae.

La Península de Araya es una de las regiones más secas del país, con un régimen de precipitación que no supera los $400 \mathrm{~mm}$ anuales (López-Monroy y Trocoli-Ghinaglia, 2014). Esto constituye un ambiente extremo de gran aridez, produciendo cambios constantes de los ambientes húmedos, lo que restringe a las especies de hábitats acuaticos a medios muy cambiantes, obligándolos a sobrevivir en pequeñas charcas, lagunas temporales o artificiales, como el caso de las lagunas de estabilización-oxidación evaluada por García et al. (2016). Este medio húmedo, artificial, representa un ambiente altamente contaminado. Los niveles de temperatura y oxígeno son oscilantes $\mathrm{y}$, con altas concentraciones de diferentes compuestos químicos, originados por la acumulación de materia orgánica, detergentes y productos hidrocarburados, contenidas en las aguas residuales estancadas, hacen de esta laguna un ambiente extremo al cual las especies deben adaptarse para sobrevivir. Por lo que las especies encontradas en este hábitat artificial (García, et al., 2016) son consideradas especies extremófilas.

En las especies de Berosus se ha observado mucha preferencia por hábitats sombreados, otras toleran las aguas someras y abiertas, incluso hay selección por algunos sustratos orgánicos, pudiendose observar abandono de los cuerpos de agua por parte de los adultos en busca de nuevos hábitats (Oliva, 2007). En la península de Araya se encuentran muy pocos cuerpos de agua dulce distribuidos entre la aridez del terreno, excepto por aquellos que son salobre o con alta concentraciones de salinidad, lo que demuestra la aceptación de este tipo de ambiente de aguas dulce pero contaminada con altas concentraciones de materia orgánicas en suspención o detritos orgánicos acumulados en el fondo, por parte de Berosus elsae sp. nov. 


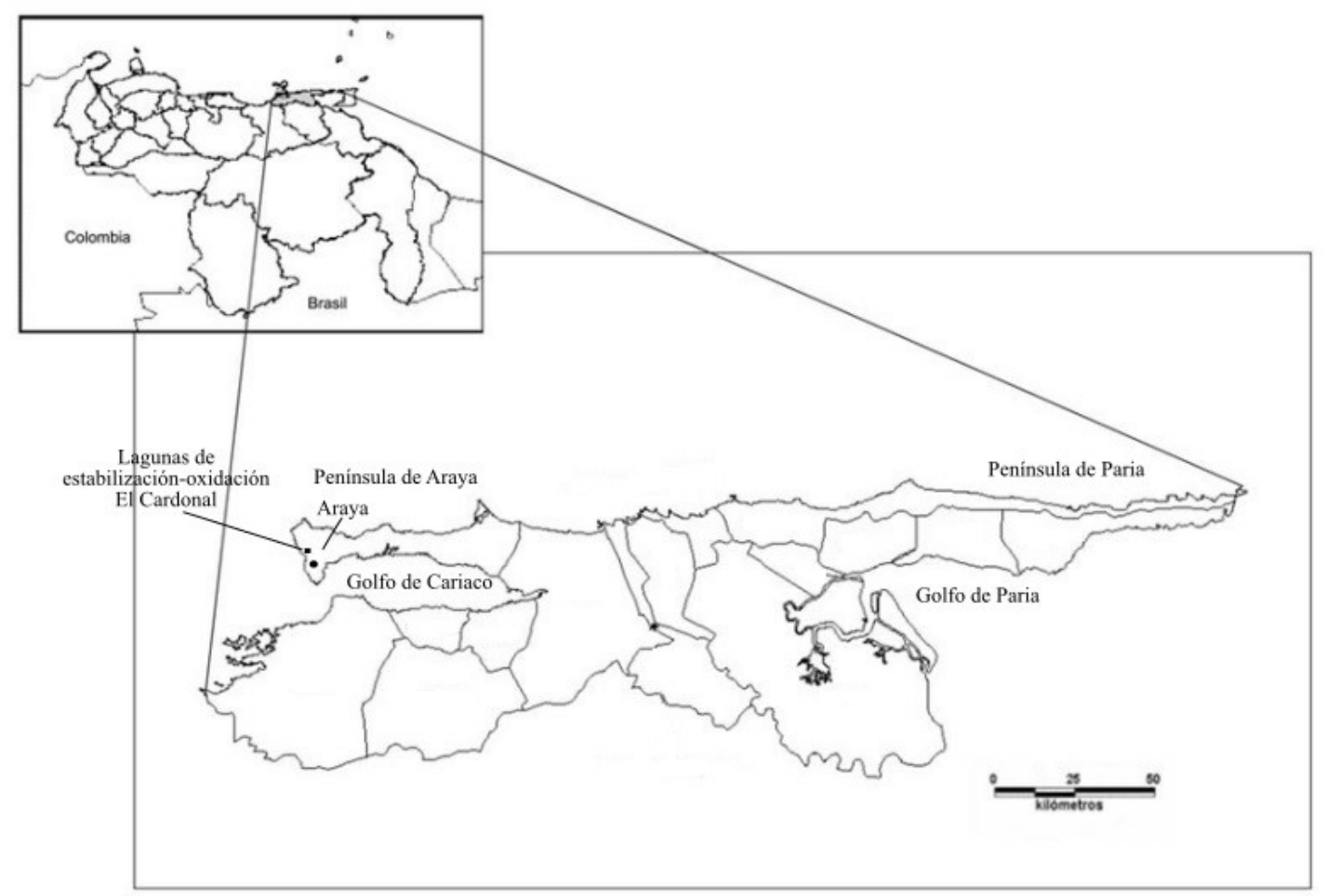

Figura 5. Mapa del estado Sucre, Venezuela. El punto negro señala el pueblo de Araya en cercanía del sistema lagunar antropogénico marcado en un pequeño rectángulo negro, en la Península de Araya.

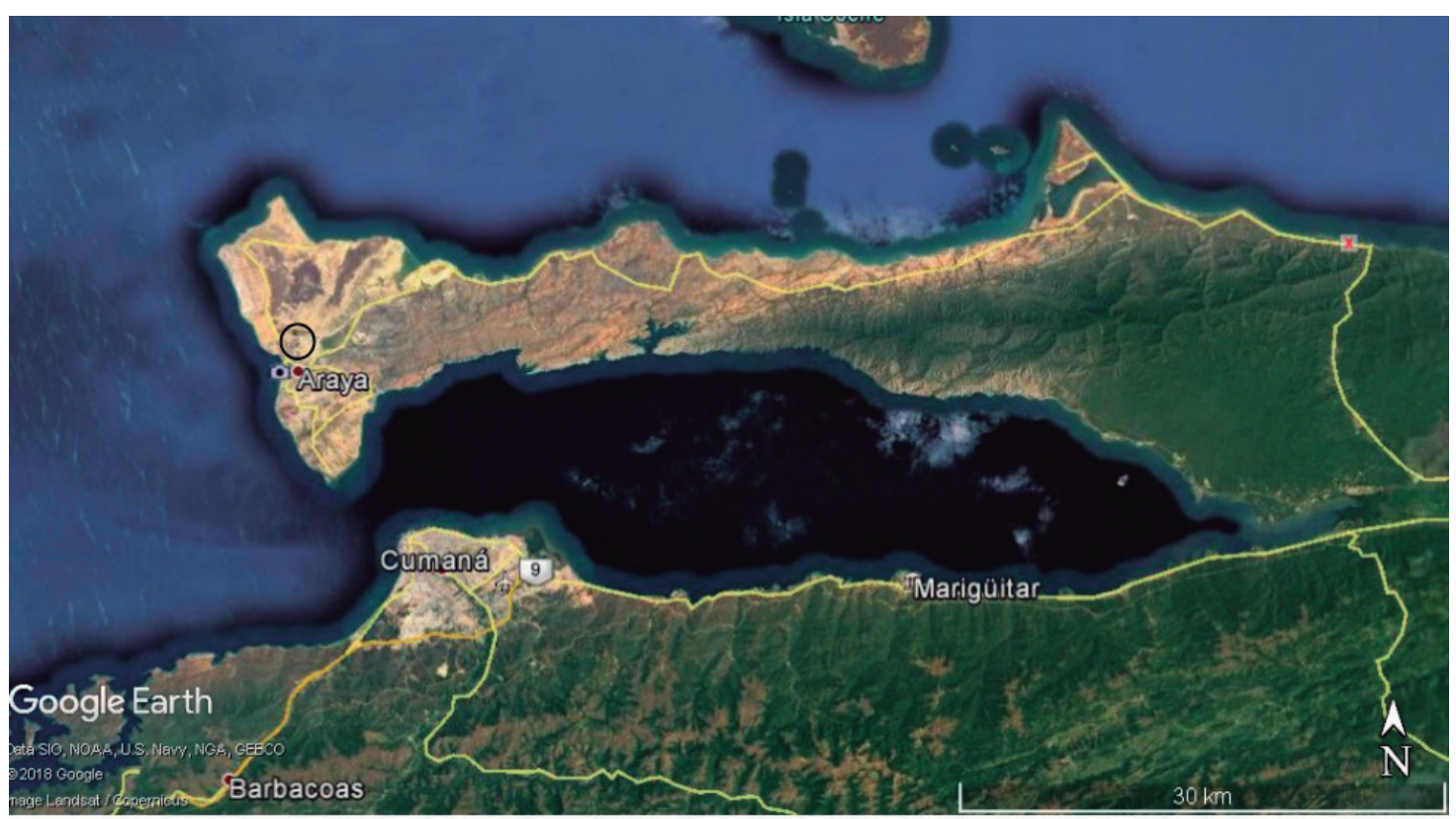

Figura 6. Imagen satelital de la península de Araya. Encerrado con circulo negro, se muestra la posición del sistema lagunar en relación a la costa caribeña. A la derecha puede observarse la cuenca del Golfo de Cariaco. 


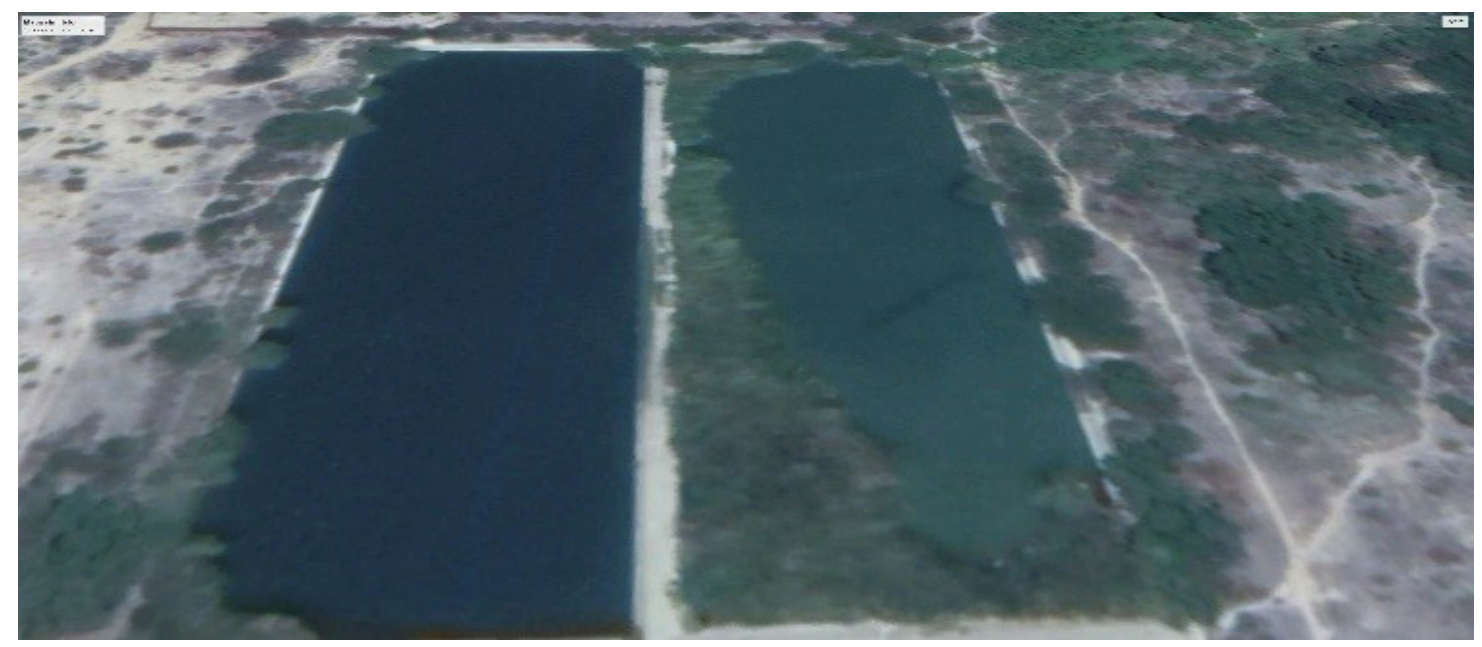

Figura 7. Sistema de lagunas antropogénicas de estabilización-oxidación "El Cardonal”.

\section{AGRADECIMIENTOS}

A mi esposa Noris Ramos, por su valioso apoyo logístico y moral, a Eduardo Boada por su valiosa colaboración durante la investigación del medio artificial de las lagunas. Para Adriana Oliva, por su aceptación en este proceso investigativo y hacerme llegar bibliografía complementaria.

\section{LITERATURA CITADA}

Hansen, M. 1999. World Catalogue of Insects. Volume 2. Hydrophiloidea (s. str.) (Coleoptera). Apollo Books, Stenstrup, 416 pp.

Cumana, L. 1999. Caracterización de las formaciones vegetales de la Península de Araya, estado Sucre, Venezuela. Saber, 11 (1): 7-16.

Deler-Hernández, A., M. Fikáček y F. Cala-Riquelme. 2013. A review of the genus Berosus Leach of Cuba (Coleoptera, Hydrophilidae). ZooKeys, 273: 73-106.

García, M., A. Vera, C. J. Benetti y L. Blanco-Belmonte. 2016. Identificación y clasificación de los microhábitats de agua dulce. Acta Zoológica Mexicana, 32 (1): 12-31.

López-Monroy, F. y L. Troccoli-Ghinaglia. 2014. Aproximación sobre la climatología de la isla de margarita y su importancia en los procesos oceánicos. Saber, 26 (4): 465-471.

Oliva, A. 1989. El género Berosus (Coleoptera: Hydrophilidae) en América del Sur. Revista del Museo Argentino de Ciencias Naturales, Entomología, 6: 57-236.

Oliva, A. 2007. Distribución de Berosini (Coleoptera: Hydrophilidae) en América del Sur. Revista de la Sociedad Entomológica Argentina, 66 (3-4): 47-56.

Oliva, A. 2014. Distribution of the species of Berosini (Coleoptera: Hydrophilidae) in South America. Revista Colombiana de Entomología, 40 (2): 272-280. 
Oliva, A. y A. E. Z. Short. 2012. Review of the Berosus Leach of Venezuela (Coleoptera, Hydrophilidae, Berosini) with description of fourteen new species. ZooKeys, 206: 1-69.

Short, A. E. Z. y M. Fikáček. 2011. World catalogue of the Hydrophiloidea (Coleoptera): additions and corrections II (2006-2010). Acta Entomologica Musei Nationalis Pragae, 51: $83-122$.

[Recibido: 19 de febrero, 2020. Aceptado para publicación: 04 de junio, 2020] 